\title{
Limb Salvage Procedure
}

National Cancer Institute

\section{Source}

National Cancer Institute. Limb Salvage Procedure. NCI Thesaurus. Code C16042.

A procedure to avoid amputation of an arm or leg 